\title{
Burr-Assisted Peripheral Superficial Keratectomy for the Treatment of Persistent Symptomatic Peripheral Corneal Edema
}

\author{
Kattayoon Kate Hashemi (D) - Emmanouil Blavakis · Mohamad El Wardani • \\ Myrsini Petrelli · Elisa D'Alessandro · Georgios Kymionis
}

Received: April 26, 2021 / Accepted: June 23, 2021 / Published online: July 20, 2021

(C) The Author(s) 2021

\section{ABSTRACT}

Purpose: To describe a simple technique of diamond burr-assisted superficial keratectomy for the treatment of peripheral corneal edema.

Cases Presentation: Two patients with persistent symptomatic peripheral corneal edema underwent superficial keratectomy with the use of a diamond ophthalmic burr. The efficacy of the treatment was evaluated clinically as well as with anterior segment optical coherence tomography. During the postoperative followup period, no adverse events were observed and corneal edema reduced significantly. The patients were asymptomatic, no epithelial cysts could be identified clinically, and visual acuity remained unchanged.

Conclusion: Peripheral superficial keratectomy could be an effective alternative for the

Supplementary Information The online version contains supplementary material available at https:// doi.org/10.1007/s40123-021-00370-1.

K. K. Hashemi ( $₫)$ · E. Blavakis · M. El Wardani M. Petrelli · E. D'Alessandro · G. Kymionis Department of Ophthalmology, Jules-Gonin Eye Hospital, University of Lausanne, Fondation Asile des aveugles, Avenue de France 15, 1002 Lausanne, Switzerland

e-mail: kattayoon.hashemi@fa2.ch

G. Kymionis

1st Department of Ophthalmology, General

Hospital "G. Gennimatas", National and

Kapodistrian University of Athens, Athens, Greece treatment of peripheral, symptomatic corneal edema.

Keywords: Bullous keratopathy; Corneal edema; Corneal scraping; Diamond ophthalmic burr; Superficial keratectomy

\section{Key Summary Points}

Peripheral corneal edema may not affect visual acuity but it can be symptomatic, especially following rupture of epithelial bullae.

Superficial keratectomy was performed with the use of the diamond ophthalmic burr in two patients with persistent symptomatic peripheral corneal edema.

Treatment successfully alleviated patients' symptoms while visual acuity was not affected.

\section{DIGITAL FEATURES}

This article is published with digital features, including a summary slide and videos, to facilitate understanding of the article. To view 
digital features for this article go to https://doi. org/10.6084/m9.figshare.14823477.

\section{INTRODUCTION}

Corneal edema results from fluid retention in the cornea and can be related to many different conditions, including corneal dystrophies, surgical trauma, direct corneal injury, intraocular inflammation, corneal hydrops, Brown-McLean syndrome, and drug toxicity [1]. Beside causing stromal tumescence and epithelial swelling, fluid accumulates between basal epithelial cells, forming blister-like structures leading to chronic irritation, discomfort, and decreased visual acuity. Furthermore, the formed bullae may rupture causing pain and increased risk of corneal infection [2].

In the early stages, conservative measures include hyperosmotic eye drops and bandage contact lenses [3, 4]. In long-standing cases, multiple treatment modalities have been used, individually or combined. In most cases, the treatment of choice is posterior lamellar or penetrating keratoplasty [5] while other techniques such as anterior stromal puncture (ASP) [6], phototherapeutic keratectomy (PTK) [7], corneal cross-linking (CXL) [8], amniotic membrane transplantation (AMT) [9], or conjunctival flaps (CF) [10] might be beneficial.

In this report, we describe the successful management of two patients with persistent symptomatic peripheral corneal edema by superficial keratectomy using a hand-held drill foreign body remover.

\section{CASE PRESENTATIONS}

\section{Case 1}

A 77-year-old female patient was referred to our institute for the management of peripheral corneal microcystic edema in her right eye following uncomplicated cataract surgery a year prior. Her past ocular history included presence of corneal guttae and cataract surgery in both eyes.
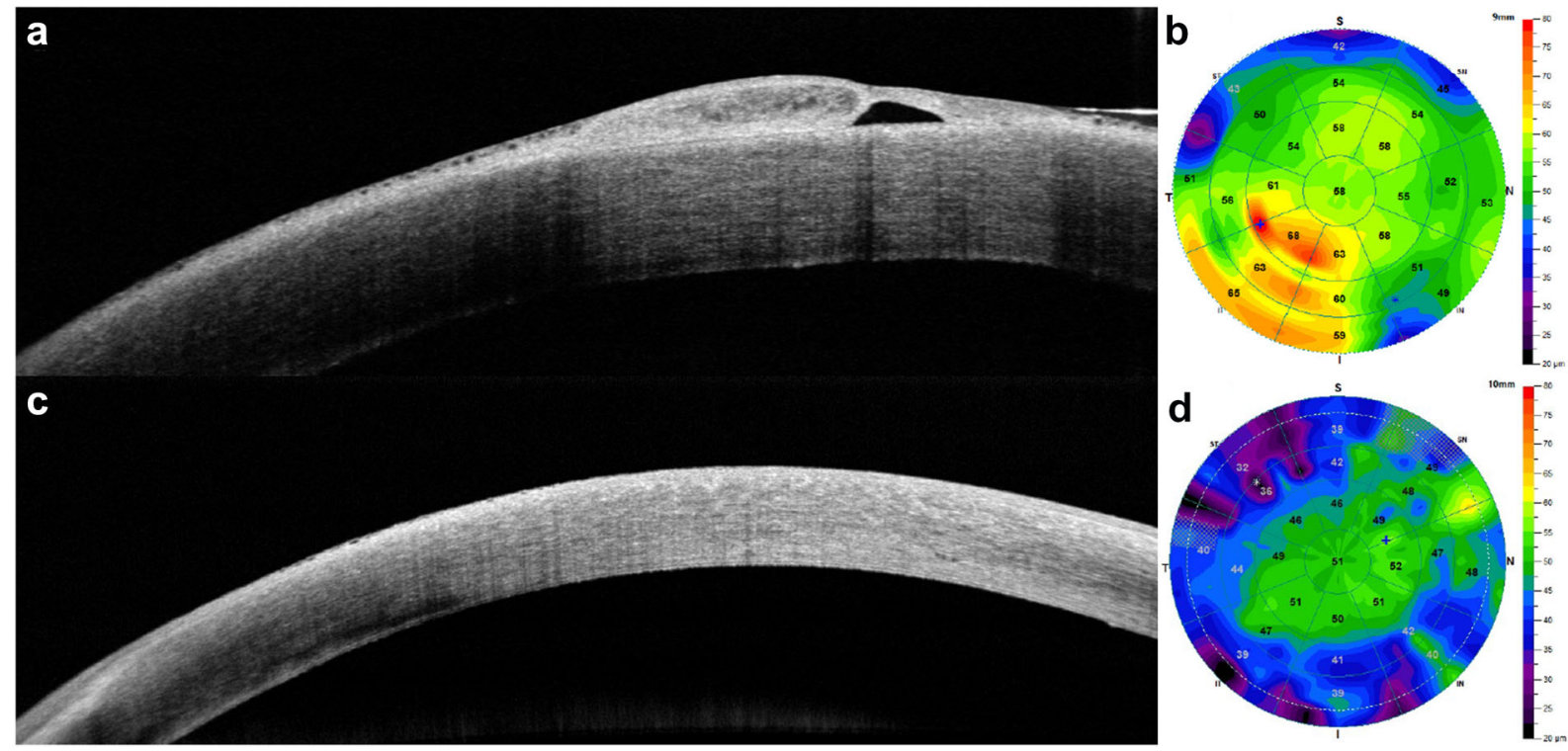

Fig. 1 a Preoperative anterior segment optical coherence tomography (AS-OCT) showing epithelial thickening and multiple intraepithelial cysts. b Preoperative epithelium map showing inferotemporal thickening of the corneal epithelium. c AS-OCT 2 months postoperatively showing marked improvement with few residual epithelial microcysts. $\mathbf{d}$ Postoperative epithelium map showing thinning of the corneal epithelium in the treated area 
Upon presentation, the patient complained of recurrent episodes of mild redness, pain, and discomfort in her right eye that were treated with topical lubricants and hypertonic solutions. Her best corrected visual acuity (BCVA) was 1.0 and 1.2 (decimal scale) in the right and left eye, respectively, and the intraocular pressure was within normal limits. Slit lamp examination revealed microcystic edema in the temporal periphery of the cornea, associated with an epithelial erosion inferiorly in the right eye and presence of corneal guttae bilaterally. Endothelial cell count (ECC) was 849 and 1039 cells $/ \mathrm{mm}^{2}$ in the right and left eye, respectively. Anterior segment optical coherence tomography (AS-OCT) (Optovue, Inc., Freemont, CA) confirmed the presence of multiple intraepithelial cysts (Fig. 1a) and increased epithelial thickness (Fig. 1b). Treatment by phototherapeutic keratectomy did not achieve long-term symptomatic relief since recurrence of the microcystic edema was noted 2 months later. Anterior stromal puncture with a fine needle was then performed, a bandage contact lens was placed, and orally administered doxycycline $50 \mathrm{mg}$ once daily was prescribed. Nevertheless, further increases in corneal edema and number of microcysts were observed, accompanied by deterioration of the patient's symptoms. For this reason, a peripheral superficial keratectomy was proposed to the patient.

The procedure was performed under local anesthesia using the diamond ophthalmic burr (The Burr, Alger Company, USA), a foreign body removal instrument that includes a diamond body spud on a low speed, low torque, batteryoperated hand-held drill. After the eye was prepped and draped in a sterile manner, the corneal epithelium was removed with an ophthalmic surgical sponge, and the Bowman's layer and the anterior stroma were polished with the diamond burr (Fig. 2a, see video 1 in the online supplementary material). A bandage contact lens (Air Optix Night \& Day Aqua, Alcon) and moxifloxacin (Vigamox, Alcon Laboratories, Inc.) eye drops were placed on the cornea. Postoperative treatment included moxifloxacin (Vigamox, Alcon Laboratories, Inc.) five times per day and fluoromethalone $0.1 \%$ (FML Liquifilm, Allergan, Inc.) four times per day that were gradually tapered.

Immediate postoperative examinations revealed a small number of microcysts restricted to the inferior cornea that regressed following instillation of sodium chloride $5 \%$ and sodium hyaluronate $0.15 \%$ (ODM 5, Horus Pharma, Inc.) four times daily. Six months after the operation, the patient reported no symptoms, mild inferior stromal scarring was observed on

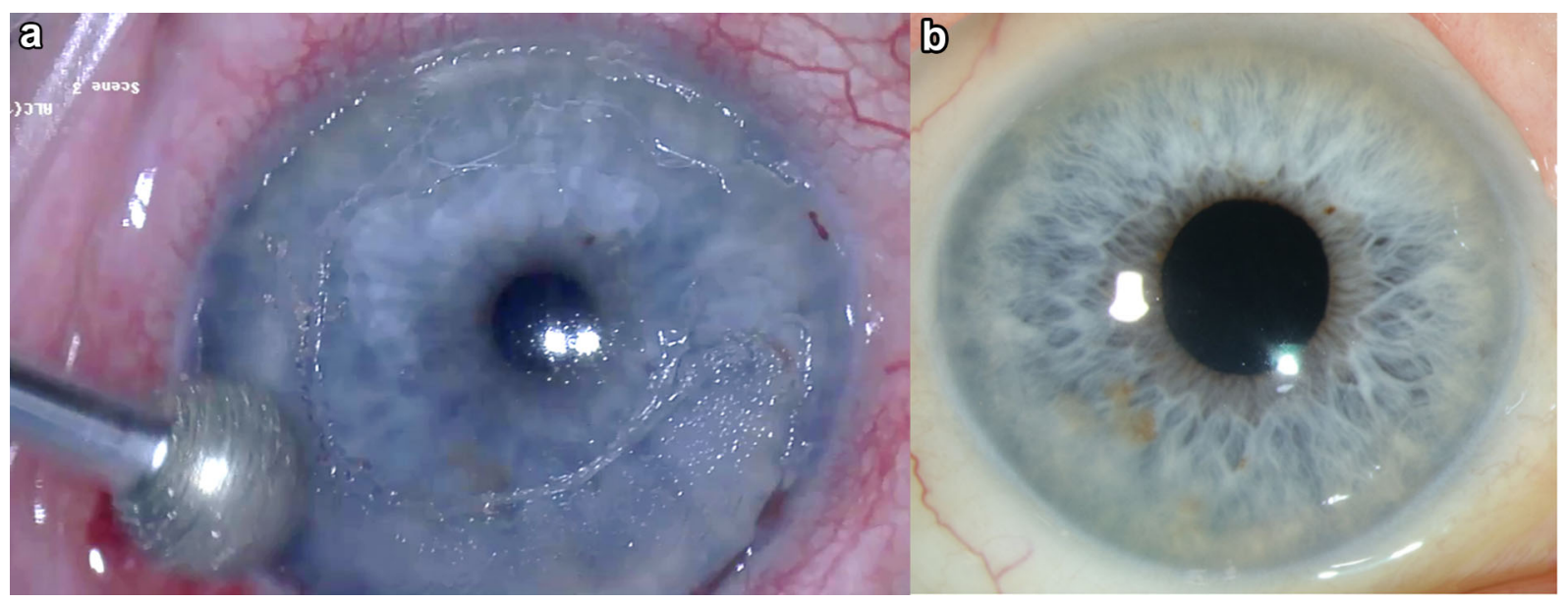

Fig. 2 a Intraoperative photo showing the treated area and the diamond burr. b Photo of the treated eye 2 months after the operation with no identifiable cysts and minimal stromal scarring inferotemporally 


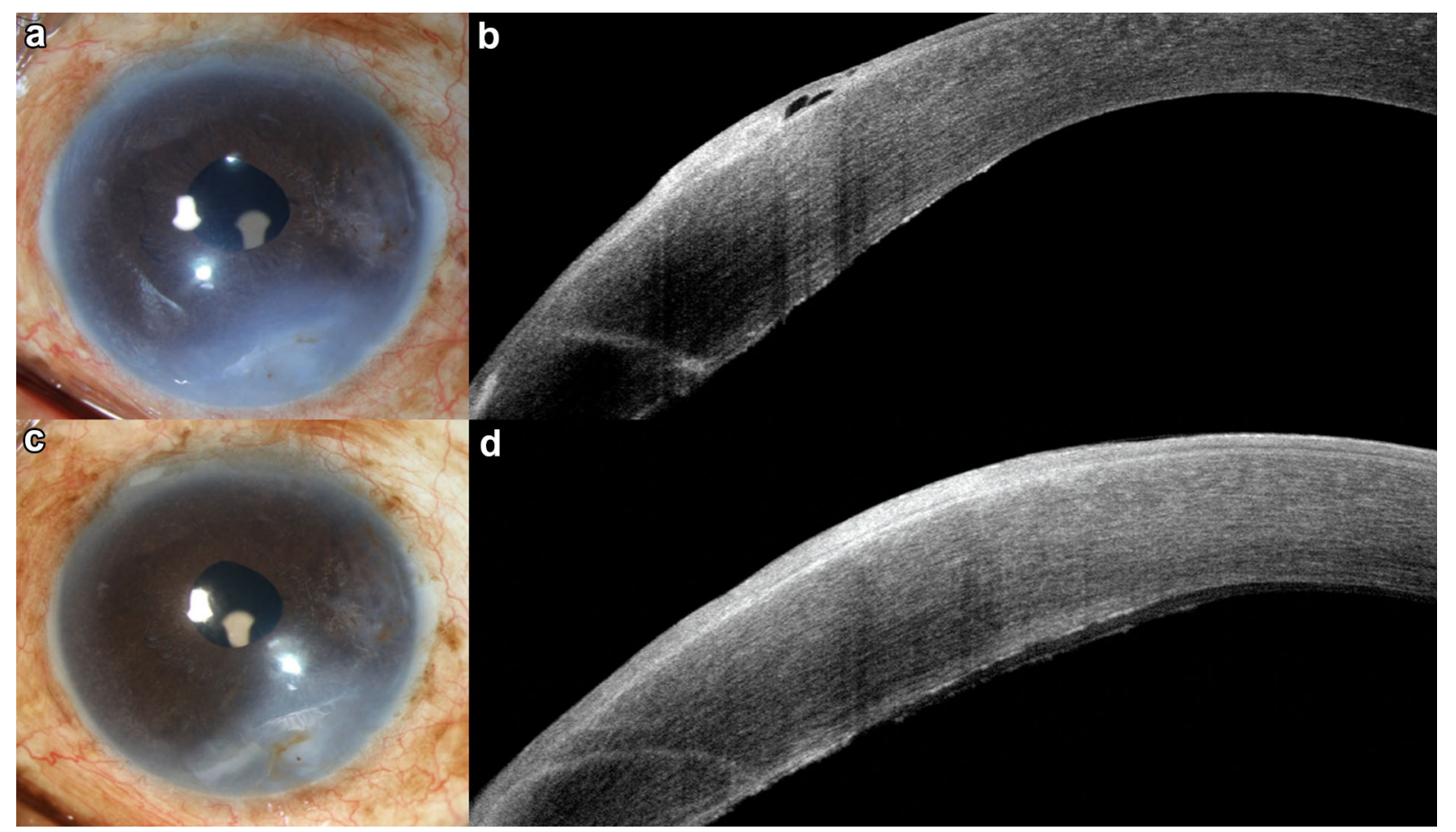

Fig. 3 a Preoperative photo of the involved eye. b Preoperative AS-OCT showing epithelial thickening and intraepithelial cysts. c Photo of the involved eye 6 months postoperatively. d AS-OCT 6 months postoperatively

slit lamp examination (Fig. 2b) while a limited number of epithelial microcysts and decreased epithelial thickness were noted by AS-OCT (Fig. 1c, d). Preoperative ECC was 783 cells $/ \mathrm{mm}^{2}$ while at 6 months postoperatively it was 657 cells $/ \mathrm{mm}^{2}$. BCVA of the affected eye remained 1.0 during the entire postoperative follow-up period.

\section{Case 2}

A 50-year-old male patient was referred to our department for further management of persistent symptomatic corneal edema in his left eye. Past medical and surgical history were significant for bilateral advanced open angle glaucoma, filtration, and cataract surgery on both eyes. Two weeks after the cataract surgery of the left eye, he suffered a blunt trauma with iris incarceration through the main port that was repaired without complication. Three months later, the patient developed peripheral showing thinning of the epithelium and the absence of intraepithelial cysts

persistent symptomatic corneal edema with bullae formation in the area of prior iris incarceration and was complaining of foreign body sensation and tearing.

On presentation, BCVA was 0.8 in both eyes and intraocular pressure was $12 \mathrm{mmHg}$ in both eyes under anti-glaucoma treatment. Slit lamp examination revealed peripheral inferotemporal corneal edema and a clear cornea centrally (Fig. 3a). AS-OCT examination revealed stromal edema with epithelial bullae formation (Fig. 3b) and a corneal thickness of $1112 \mu \mathrm{m}$ in the affected area. Endothelial cell count was 2415 and $1090 \mathrm{cell} / \mathrm{mm}^{2}$ in the right and left eye respectively.

Because of the good central vision, minimal invasive treatment options were discussed and a peripheral superficial keratectomy using the diamond burr was performed on the slit lamp with local anesthesia (see video 2 in the online supplementary material). A bandage contact lens was placed on the cornea and antibiotic 
treatment with moxifloxacin (Bayer AG, Germany) five times per day was prescribed until the epithelium healed.

On last follow-up examination, 6 months postoperatively, the patient was asymptomatic and BCVA of the affected eye was 0.8. Slit lamp examination revealed anterior stromal scarring in the treated region (Fig. 3c) and AS-OCT confirmed the absence of epithelial cysts or bullae (Fig. 3d). Preoperative ECC was 1090 cells $/ \mathrm{mm}^{2}$ while at 6 months postoperatively it was 1083 cells $/ \mathrm{mm}^{2}$.

Written informed consent for publication of both patients' clinical details was obtained. An ethics committee approval was not required for the completion of this study.

\section{DISCUSSION}

Persistent corneal edema can be associated with foreign body sensation, redness, pain, tearing and photophobia, aside from reduced visual acuity. The main goal of treatment is to relieve symptoms and improve visual acuity, when possible. Bandage contact lens and hyperosmotic agents help to reduce symptoms temporarily. Anterior stromal puncture is a repeatable slit lamp procedure that can be used in early, localized and peripheral cases [6]. However, it is not applicable in large areas of corneal edema, it is associated with an increased risk of perforation, and it cause excessive stromal scarring that might affect the patient's vision [11].

Excimer laser PTK has been demonstrated to be successful in symptomatic relief and epithelial adhesion. Interestingly, deeper ablation (up to $25 \%$ of stromal thickness) has been shown to be more successful in decreasing pain than shallow ablation, possibly owing to more extensive removal of corneal neural plexus components [12]. The effect of corneal collagen cross-linking on pain reduction and visual acuity improvement has also been studied but despite the amelioration observed shortly after the operation, there was not any long-term benefit [8]. In eyes with good visual potential, corneal transplantation is considered to be the gold standard, especially with the introduction of Descemet membrane endothelial keratoplasty (DMEK) and Descemet stripping automated endothelial keratoplasty (DSAEK) that are more effective than penetrating keratoplasty [5]. The advantage of endothelial keratoplasties is they address the primary pathology of the corneal edema by replacing the decompensated endothelium and they can achieve satisfying visual acuity results. However, they cannot be used for the management of localized peripheral corneal edema since only the central part of the corneal endothelium is usually replaced.

Amniotic membrane transplantation has been found to be equally effective compared to anterior stromal puncture and PTK in terms of symptom relief in patients with bullous keratopathy (BK) but its use is limited to cases where visual acuity cannot be restored [9]. Conjunctival flaps represent another option for these patients since they have very good results in alleviating ocular pain and discomfort but they may be related to several complications such as flap retraction [10]. Lastly, in blind eyes with $\mathrm{BK}$, intracorneal silicone oil insertion has also been shown to result in immediate symptomatic relief [13].

The authors postulate that the mechanism of action of superficial keratectomy is similar to ASP. The debridement and mechanical friction on the Bowman membrane and anterior stroma may increase the expression of extracellular proteins such as type IV collagen, fibronectin, and laminin, which in turn lead to heavier scarring and better adhesion of the epithelium to the underlying stroma [14]. Anterior corneal scraping with the ophthalmic burr might be an alternative to ASP because of the large area that can be treated in a uniform manner and the eliminated risk of perforation. In addition, in the two presented cases, superficial keratectomy did not affect the corneal endothelium since ECC continued its slow decreasing rate in the first case and remained unchanged in the second. However, during the operation, the surgeon should exercise caution to avoid scraping the limbus and damaging the limbal stem cells.

In conclusion, we describe a simple technique that might be successful in treating patients with painful, refractory, peripheral corneal edema. Despite the favorable outcome 
and the absence of complications in these two cases, further investigation of this technique is required to assess its long-term efficacy and safety.

\section{ACKNOWLEDGEMENTS}

The authors would like to thank the patients for their willingness to participate in the advancement and dissemination of knowledge.

Funding. No funding or sponsorship was received for this study or publication of this article. The Rapid Service Fee was funded by the authors.

Authorship. All named authors meet the International Committee of Medical Journal Editors (ICMJE) criteria for authorship for this article, take responsibility for the integrity of the work as a whole, and have given their approval for this version to be published.

Authorship contributions. Study conception and design: Kattayoon Hashemi, Mohamed El Wardani, Georgios Kymionis. Data collection: Emmanouil Blavakis, Mohamed El Wardani, Myrsini Petrelli, Elisa D'Alessandro. First draft of the manuscript: Kattayoon Hashemi, Emmanouil Blavakis, Mohamed El Wardani, Myrsini Petrelli, Elisa D'Alessandro. Comments on previous versions of the manuscript: Kattayoon Hashemi, Myrsini Petrelli, Georgios Kymionis. All authors read and approved the final manuscript.

Disclosures. All authors declare that they have no conflict of interest.

Compliance with Ethics Guidelines. Written informed consent for publication of both patient's clinical details was obtained. An ethics committee approval was not required for the completion of this study.

Data availability. Data sharing is not applicable to this article as no datasets were generated or analyzed during the current study.
Open Access. This article is licensed under a Creative Commons Attribution-NonCommercial 4.0 International License, which permits any non-commercial use, sharing, adaptation, distribution and reproduction in any medium or format, as long as you give appropriate credit to the original author(s) and the source, provide a link to the Creative Commons licence, and indicate if changes were made. The images or other third party material in this article are included in the article's Creative Commons licence, unless indicated otherwise in a credit line to the material. If material is not included in the article's Creative Commons licence and your intended use is not permitted by statutory regulation or exceeds the permitted use, you will need to obtain permission directly from the copyright holder. To view a copy of this licence, visit http:// creativecommons.org/licenses/by-nc/4.0/.

\section{REFERENCES}

1. Levenson JE. Corneal edema: cause and treatment. Surv Ophthalmol. 1975;20:190-204.

2. Morishige N, Sonoda KH. Bullous keratopathy as a progressive disease: evidence from clinical and laboratory imaging studies. Cornea. 2013;32(Suppl 1): S77-83.

3. Chow SC, Chan JC. Review on the use of topical ocular hypertonic saline in corneal edema. Cornea. 2021;40(4):533-9.

4. Andrew NC, Woodward EG. The bandage lens in bullous keratopathy. Ophthalmic Physiol Opt. 1989;9:66-8.

5. Woo JH, Ang M, Htoon HM, Tan D. Descemet membrane endothelial keratoplasty versus descemet stripping automated endothelial keratoplasty and penetrating keratoplasty. Am J Ophthalmol. 2019;207:288-303.

6. Sridhar MS, Vemuganti GK, Bansal AK, Rao GN. Anterior stromal puncture in bullous keratopathy: a clinicopathologic study. Cornea. 2001;20:573-9.

7. Thomann U, Meier-Gibbons F, Schipper I. Phototherapeutic keratectomy for bullous keratopathy. Br J Ophthalmol. 1995;79:335-8. 
8. Choy BNK, Ng ALK, Zhu MM, Liu CC, Xu S, Lai JSM. Randomized control trial on the effectiveness of collagen cross-linking on bullous keratopathy. Cornea. 2020;39:1341-7.

9. Paris Fdos S, Gonçalves ED, Campos MS, Sato EH, Dua HS, Gomes JÁ. Amniotic membrane transplantation versus anterior stromal puncture in bullous keratopathy: a comparative study. $\mathrm{Br} \mathrm{J}$ Ophthalmol. 2013;97:980-4.

10. Güell JL, Morral M, Gris O, Elies D, Manero F. Treatment of symptomatic bullous keratopathy with poor visual prognosis using a modified Gundersen conjunctival flap and amniotic membrane. Ophthalmic Surg Lasers Imaging. 2012;43:508-12.

11. Fernandes M, Moreker MR, Shah SG, Vemuganti GK. Exaggerated subepithelial fibrosis after anterior stromal puncture presenting as a membrane. Cornea. 2011;30:660-3.

12. Maini R, Sullivan L, Snibson GR, Taylor HR, Loughnan MS. A comparison of different depth ablations in the treatment of painful bullous keratopathy with phototherapeutic keratectomy. Br J Ophthalmol. 2001;85:912-5.

13. Kymionis GD, Diakonis VF, Kankariya VP, et al. Femtosecond laser-assisted intracorneal biopolymer insertion for the symptomatic treatment of bullous keratopathy. Cornea. 2014;33:540-3.

14. Hsu JK, Rubinfeld RS, Barry P, Jester JV. Anterior stromal puncture immunohistochemical studies in human corneas. Arch Ophthalmol. 1993;111: 1057-63. 